\title{
Notes on the vocalizations of Lemon-chested Greenlet (Hylophilus thoracicus)
}

Peter Boesman

In the following we briefly analyze and compare voice of the three races of Lemon-chested Greenlet (Hylophilus thoracicus). We also try to quantify the extent of any vocal differences using the criteria proposed by Tobias et al. (2010), as a support for taxonomic review. We have made use of sound recordings available on-line from Xeno Canto (XC).

Song phrase in all races is structurally the same: a single, double or triple note repeated typically 5-10 times at a fast pace, with an initial increase in amplitude and an abrupt ending. This repeated note seems to be amazingly variable. Some examples per race: aemulus

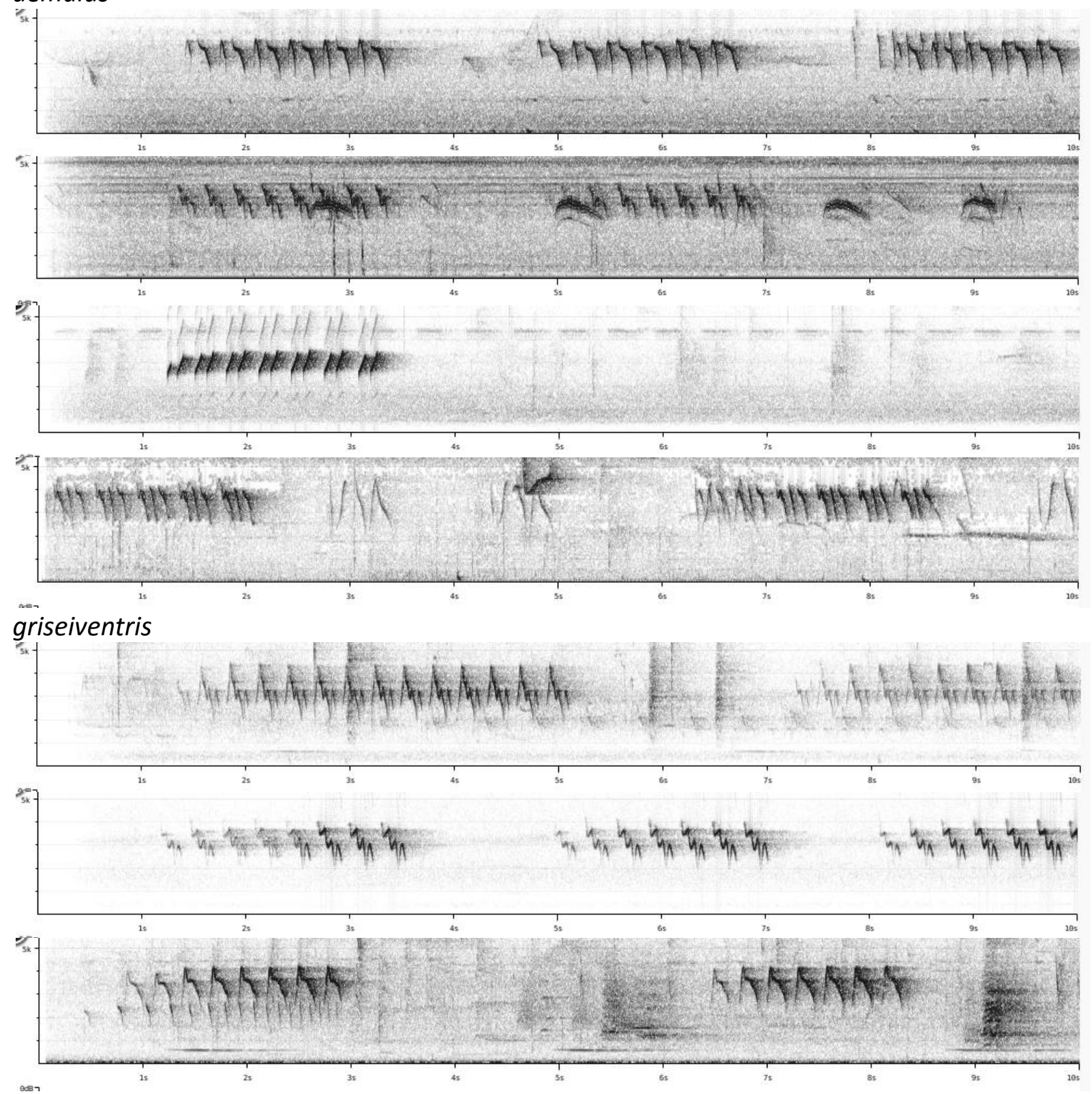


HANDBOOK OF THE

Alive ORNITHOLOGICAL NOTES
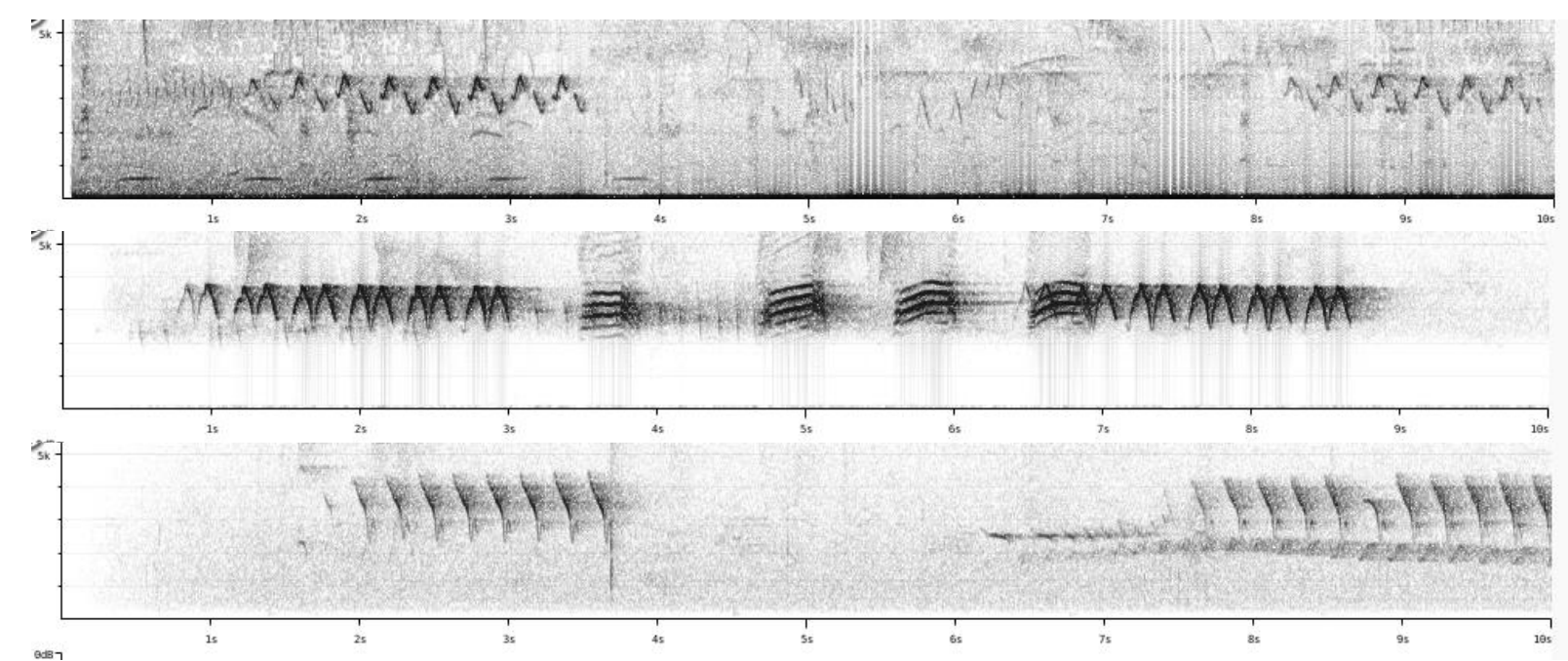

thoracicus (disjunct race in SE Brazil)
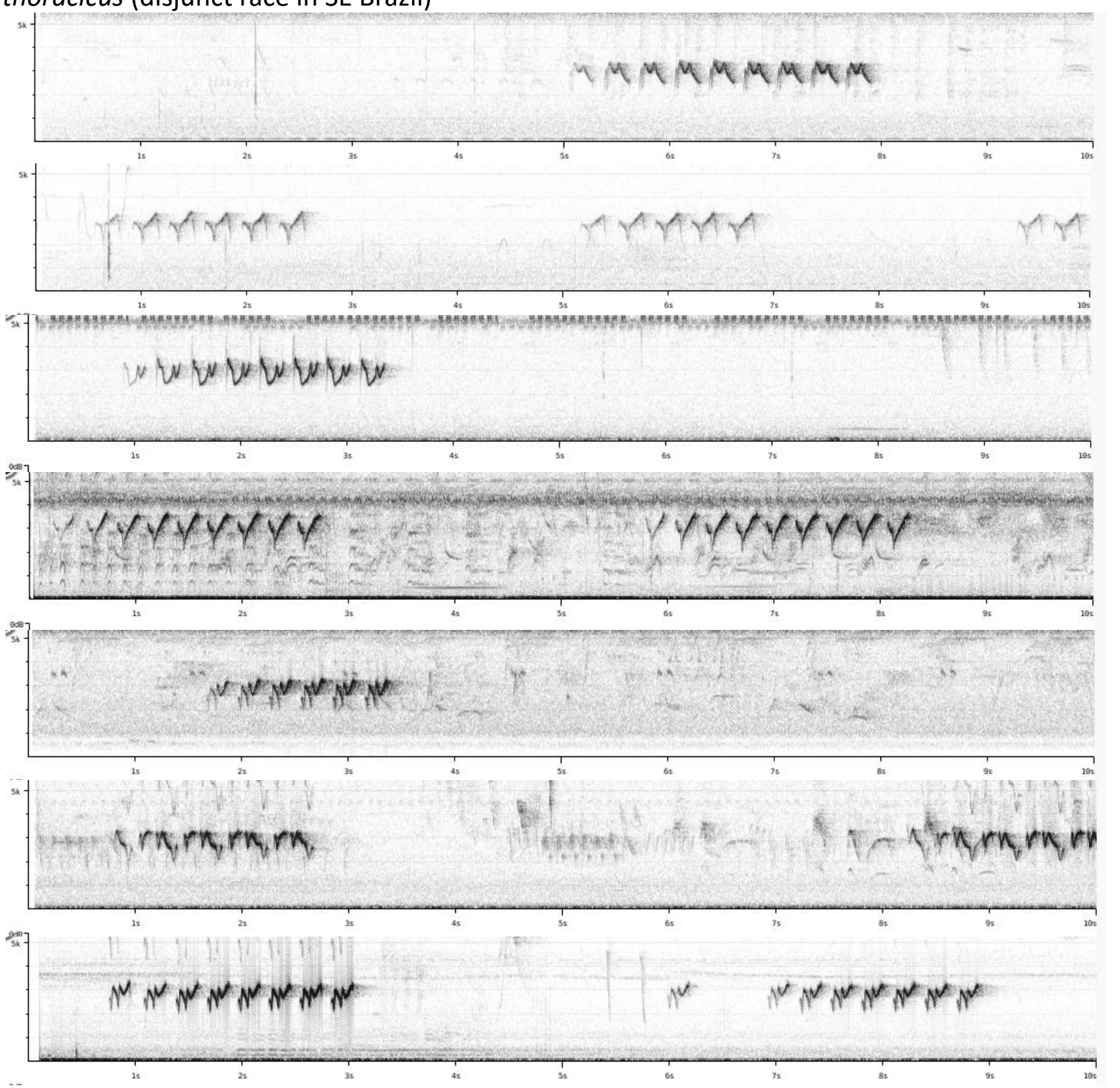

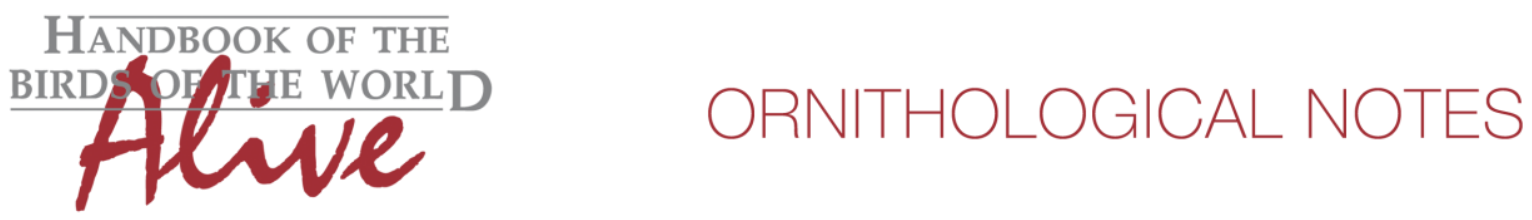

There is so much difference in note shape, that we haven't found any clear pattern that would allow to distinguish any of the three races.

The only difference we have found is that birds of SE Brazil (thoracicus) sing notes which reach $3200-3900 \mathrm{~Hz}$ as a maximum frequency, while aemulus/griseiventris typically reaches $3700-4600 \mathrm{~Hz}$ (with a few exceptions). The separated population of S Bahia sings similar to other SE Brazilian birds.

Given there is significant overlap in the data ranges of maximum frequency, when applying Tobias criteria, this would lead to a vocal score of 1 (or2 at most).

This note was finalized on 21st October 2015, using sound recordings available on-line at that moment. We would like to thank in particular the sound recordists who placed their recordings for this species on XC: Peter Boesman, Paul Coopmans, Eric DeFonso, Richard Hoyer, Joe Klaiber, Niels Krabbe, Dan Lane, Jeremy Minns, John V Moore, Cedric Mroczko, Leonardo Pimentel, Alexandre Renaudier, Christian Regis da Silva, Robert Ridgely, Eduardo Schultz,

\section{References}

Tobias, J.A., Seddon, N., Spottiswoode, C.N., Pilgrim, J.D., Fishpool, L.D.C. \& Collar, N.J. (2010). Quantitative criteria for species delimitation. Ibis 152(4): 724-746.

\section{Recommended citation}

Boesman, P. (2016). Notes on the vocalizations of Lemon-chested Greenlet (Hylophilus thoracicus). HBW Alive Ornithological Note 173. In: Handbook of the Birds of the World Alive. Lynx Edicions, Barcelona. (retrieved from http://www.hbw.com/node/932105 on 20 August 2016). 